\title{
LA GESTIÓN DE LOS RESIDUOS DOMÉSTICOS EN LOS ANTIGUOS VERTEDEROS DE LA COMARCA DE LA RIBERA D'EBRE (CATALUÑA)
}

\author{
Òscar Saladié \\ Grupo de Investigación de Análisis Territorial y Estudios Turísticos \\ Departamento de Geografía. Universitat Rovira i Virgili
}

\section{RESUMEN}

Con anterioridad a la existencia de los vertederos controlados y las plantas de incineración los residuos domésticos eran transportados hasta unos terrenos más o menos próximos a los núcleos de población donde quedaban a la intemperie pudiendo en algunos casos ser quemados, con las implicaciones ambientales que este tipo de gestión conlleva. En la elección de los terrenos del vertedero tampoco se había tenido en cuenta ningún aspecto de carácter ambiental. En la comarca catalana de La Ribera d'Ebre estos vertederos estuvieron en funcionamiento hasta la segunda mitad de los años 90 del siglo XX cuando fueron clausurados en paralelo a la construcción de un vertedero controlado comarcal. Estos antiguos vertederos, una vez localizados, se han analizado teniendo en cuenta sus características, las del entorno donde se encontraban y la proximidad y accesibilidad al núcleo de población desde donde eran transportados los residuos. También se hace referencia al proceso de clausura y sellado de los vertederos y a la situación actual de los terrenos que los albergaron.

Palabras clave: residuos domésticos, vertederos, comarca de La Ribera d'Ebre.

\section{ABSTRACT}

Final management of domestic waste by means of a landfill or an incinerator plant is relatively recent in time. Previously domestic waste was transported to an area near to the town where it was deposed on land (dump) and in some cases burned with the environmental implications that this kind of management carries. Environmental aspects

\footnotetext{
Este trabajo ha sido posible gracias a una ayuda del Institut Ramon Muntaner (IRMU) y a una beca del Centre d'Estudis de la Ribera d'Ebre (CERE). Está enmarcado en el proyecto «Turismo, movilidad residencial y competitividad territorial. Respuesta locales a las dinámicas de cambio global» (GLOBALTUR), CSO201123004/GEOG, financiado por el Ministerio de Ciencia e Innovación. También ha contado con la colaboración de la Cátedra Dow/URV de Desarrollo Sostenible. Finalmente, el auytor desea agradecer al Consell Comarcal de La Ribera d'Ebre la información facilitada.
} 
neither were taken into account when dump localization were decided. In the Catalan county of Ribera d'Ebre this kind of dumps were working until the second half of 90's of the 20 th century when they were closed. At the same time domestic waste were sent to a landfill where waste was deposited into land. Old dumps have been located and analysed according their characteristics as well as surrounding characteristics and accessibility. Closing and sealed process is also evaluated and situation of the area at present is shown.

Key words: domestic waste, dump, Ribera d'Ebre county.

\section{Introducción}

Todas las actividades humanas, incluidas las puramente biológicas, generan subproductos que pueden no tener valor y que a su vez pueden ser nocivos tanto para la salud humana como para el medio ambiente en general (López, 1997). Por esta razón si no se quiere correr el riesgo de generar un grave problema ambiental es necesario llevar a cabo una gestión adecuada de todas estas sustancias que en conjunto denominamos residuos. Dentro del amplio espectro existente se encuentran los llamados genéricamente residuos municipales (domésticos y asimilables) que se corresponden con la categoría número 20 del Catálogo Europeo de Residuos. El objetivo de las diferentes administraciones con competencias en la gestión de los residuos municipales es reducir su volumen total y que la mayor parte pueda ser recuperada. La llamada «triple R»: reducir, reutilizar y reciclar, son los tres pilares fundamentales para hacer frente a los problemas medioambientales que ocasiona la cada vez mayor proliferación de residuos. Desde el Programa de las Naciones Unidas para el Medio ambiente (PNUMA), se añaden tres más: repensar los productos y sus funciones, reemplazar las sustancias peligrosas y reparar a partir de un diseño que facilite esta reparación y que de este modo se alargue la vida del producto. Saladié (2011), en un estudio reciente, estableció el grado de sostenibilidad territorial de Cataluña y de sus 41 comarcas mediante un indicador que combina la cantidad de residuos municipales generados con la cantidad de estos que son recogidos selectivamente en origen.

Existe una fracción de los residuos municipales que por sus características no se puede valorizar pero que también debe ser gestionada de una manera adecuada, ya sea en vertederos controlados o en plantas incineradoras. Con anterioridad a estos tipos de instalaciones los residuos municipales se vertían de manera poco controlada en terrenos periféricos a las poblaciones (barrancos o campos) donde no se habían tenido en cuenta criterios medioambientales en el momento de escogerlos como lugar de disposición de residuos. En estos emplazamientos los residuos quedaban a la intemperie y en muchos casos se quemaban para reducir su volumen, convirtiéndose en una fuente potencial de degradación de los diferentes sistemas que conforman el medio natural (atmósfera, suelos, aguas y biosfera), y en un potencial foco de enfermedades e infecciones. En primer lugar podemos hablar del impacto visual provocado por montañas de residuos acumulados en muchos casos relativamente cerca de los núcleos de población y por la posible dispersión de estos residuos debido al viento. A continuación hay que tener en cuenta los malos olores que provoca la descomposición de los residuos. En este tipo de vertederos la presencia tanto de insectos como de roedores es permanente, cosa que los convierte en un foco potencial de enfermedades infecciosas. La quema de los residuos provoca humos que contribuyen a la contaminación atmosférica, y a esto hay que sumarle el riesgo de incendios forestales, que pueden ser causados tanto por un descuido durante la quema como también por una combustión espontánea debida a la fermentación de los residuos acumulados. Por otro lado, la misma naturaleza de los 
residuos y el hecho de que se depositen directamente sobre el suelo pueden provocar la contaminación de los suelos. Además, debido a la permeabilidad de algunos suelos, unos subproductos de los residuos llamados líquidos lixiviados pueden llegar a contaminar las aguas subterráneas en el caso de que el vertedero se encuentre encima de un acuífero.

En Cataluña, estos vertederos «no controlados» se fueron clausurando en paralelo a la entrada en funcionamiento de vertederos controlados y de plantas incineradoras. La comarca de La Ribera d'Ebre no fue una excepción, casi todos sus municipios tuvieron este tipo de vertederos donde iban acumulando los residuos. Estuvieron en funcionamiento hasta la segunda mitad de los años 90 del siglo XX, cuando siguiendo las directrices del Departament de Medi Ambient de la Generalitat de Catalunya, estos vertederos de propiedad municipal se fueron clausurando. A partir de entonces, los residuos municipales de esta comarca recogidos de manera no selectiva se empezaron a trasladar al vertedero controlado comarcal situado en el término municipal de Tivissa que entró en funcionamiento en 1994. Este vertedero progresivamente fue dando servicio a los municipios de La Ribera d'Ebre y a los de las comarcas colindantes de La Terra Alta y El Priorat.

Tomando como punto de partida la información expuesta hasta aquí, el objetivo de este estudio es localizar e inventariar los antiguos vertederos municipales de residuos existentes en la comarca catalana de La Ribera d'Ebre antes de la construcción en 1994 del vertedero controlado comarcal y analizar su localización desde un punto de vista ambiental. Dar a conocer estos espacios, analizar la gestión de los residuos en los mismos y ver en qué situación se encuentran actualmente debería formar parte de las estrategias que desde las administraciones se llevan a cabo para concienciar a la población de la necesidad de generar una menor cantidad de residuos y de reciclar la mayor parte de estos.

Una vez contextualizado el tema y planteados los objetivos, en un segundo apartado se hace una breve reseña del área de estudio, para a continuación mostrar la metodología y las fuentes a partir de las cuales se ha obtenido la información. Seguidamente se encuentra un cuarto apartado con información general sobre la gestión de los residuos tanto en la comarca de La Ribera d'Ebre como en el conjunto de Cataluña. Es en el quinto apartado donde se encuentran los resultados principales de este estudio con la información sobre los antiguos vertederos: proximidad a los núcleos urbanos, características del entorno del emplazamiento, tipología de las ubicaciones escogidas, la gestión de los residuos y situación actual de los terrenos que albergaron los vertederos. Finalmente hay un apartado dedicado a las conclusiones, y un último con la bibliografía.

\section{2. Área de estudio}

La comarca de La Ribera d'Ebre se encuentra situada en el sur de Cataluña, tiene una superficie de $827,3 \mathrm{~km}^{2}$ y el río Ebro es su eje vertebrador. La población de la comarca en el año 2010 era de 24082 habitantes. La población se ha recuperado respecto al año 2001 cuando se tocó fondo con únicamente 21951 habitantes, aumento debido principalmente al saldo migratorio. Pero la población actual aún está por debajo de la del año 1977 (25099), pico máximo relacionado con la construcción de las centrales nucleares de Ascó, y mucho más por debajo si nos remontamos a los años 20 del siglo pasado cuando se superaban los 30000 habitantes. La población está distribuida en 14 municipios (Figura 1). El municipio de Tivissa está compuesto por las poblaciones de Darmós, Llaberia, La Serra d'Almos y Tivissa. Solamente la capital comarcal, Móra d'Ebre, supera en la actualidad los 5000 habitantes. En tres municipios (Móra d'Ebre, Flix y Móra la Nova) reside más de la mitad de la población de la comarca. La distribución de la población por grandes grupos de edad muestra que el $12,6 \%$ tiene menos de 15 años mientras que los mayores de 64 representan un 22,1\%. 


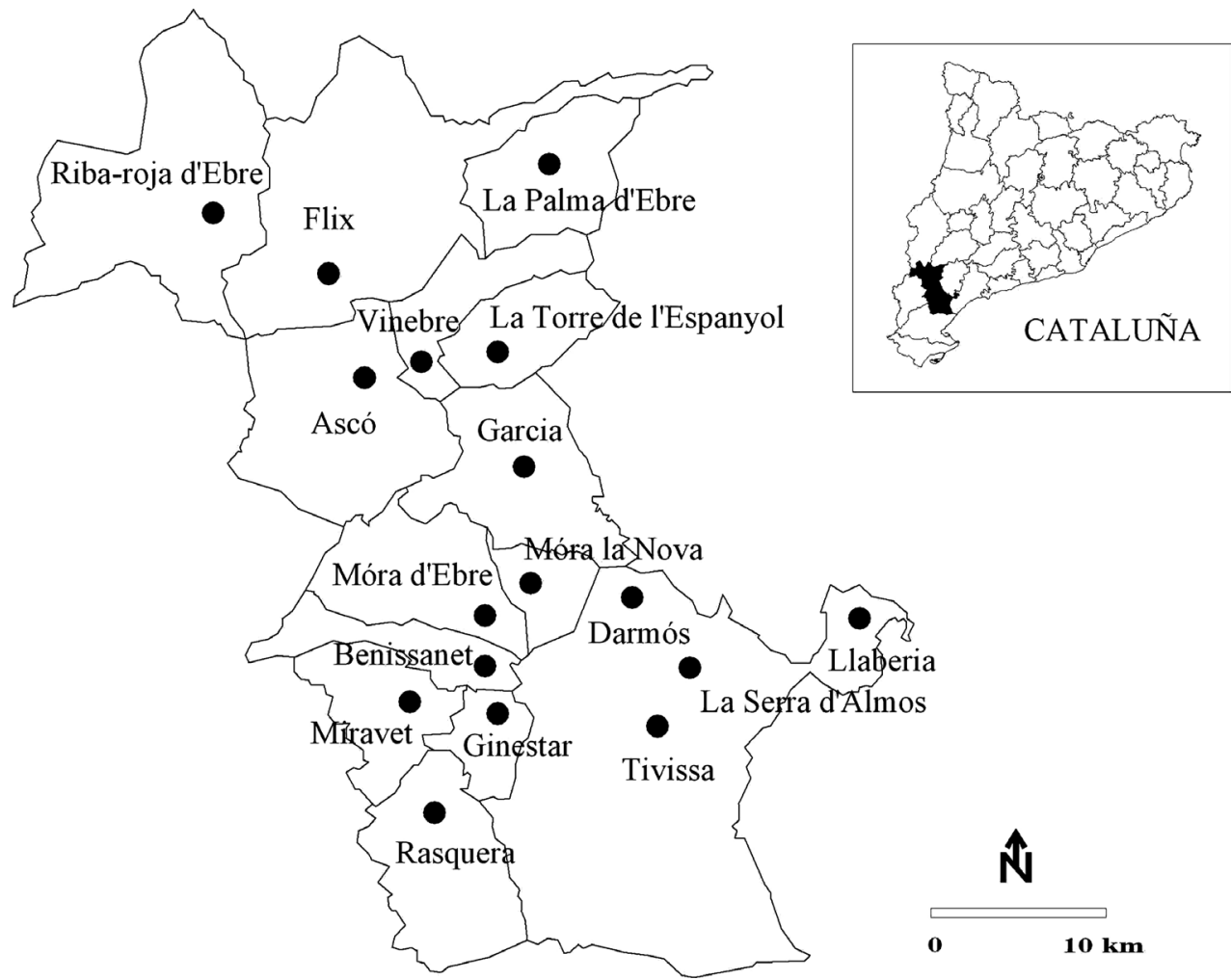

Figura 1. La comarca de La Ribera d'Ebre. Elaboración propia.

Aunque es en el sector servicios donde hay un mayor porcentaje de población activa, el peso del sector industrial es importante sobretodo en referencia al PIB. En el año 2009 el peso del sector industrial en el PIB comarcal era del 56,3\% (Anuari Econòmic Comarcal Catalunya Caixa, 2010), en buena parte debido a la presencia de la central nuclear de Ascó. En consecuencia el producto interior bruto (PIB) por cápita de la comarca representa un $191,6 \%$ del promedio de Cataluña. Ahora bien, la renta familiar bruta disponible (RFBD) por cápita solo equivale al $97 \%$ del valor del conjunto de Cataluña.

\section{Materiales y métodos}

La primera cuestión en el momento de abordar este trabajo era saber dónde estaban localizados los antiguos vertederos de las diferentes poblaciones de la comarca de La Ribera d'Ebre. Así pues, el primer lugar de contacto fueron los diferentes ayuntamientos de dicha comarca. Contacto que se hizo telefónicamente y que dio como resultado conocer que no todos los pueblos de esta comarca habían dispuesto de vertedero de residuos, como mínimo en los años previos a la entrada en funcionamiento del vertedero controlado comarcal en 1994, sino que algunos transportaban los residuos hasta el vertedero del pueblo vecino.

La segunda pregunta que se planteaba, una vez establecidos qué pueblos tenían vertedero municipal en los años 90 del siglo XX, era definir qué información había que 
obtener de cada uno de ellos. De acuerdo con el objetivo del trabajo la información es la siguiente:

- Localización del emplazamiento y situación respecto al casco urbano.

- Datos geográficos: latitud y longitud.

- Características del entorno: usos del suelo y accesos.

- Características del vertedero: propiedad, superficie, morfología y materiales del suelo.

- Gestión de los residuos: disposición al aire libre, soterramiento, combustión o combinación de alguna de las anteriores.

- Clausura y sellado del vertedero y situación actual del terreno.

Y una tercera cuestión era saber dónde se puede obtener toda esta información. La respuesta en este caso es evidente: ayuntamientos de los municipios de la comarca, Consell Comarcal de la Ribera d'Ebre (la clausura de los vertederos la realizó este ente supramunicipal) y a partir de la visita in situ a los diferentes emplazamientos. Así pues, para la consecución del objetivo planteado en el apartado introductorio se ha llevado a cabo una minuciosa búsqueda documental sobre los vertederos de los diferentes pueblos de la comarca de La Ribera d'Ebre y un exhaustivo trabajo de campo. La combinación de dichas tareas ha permitido recopilar una gran cantidad de información sobre los antiguos vertederos de residuos. Una vez conseguida toda la información necesaria el siguiente paso ha sido generar una base de datos para llevar a cabo el posterior análisis. En este trabajo no se muestran las características de cada vertedero de manera individual sino que se analizan la características generales teniendo en cuenta las diferentes tipologías y mostrando ejemplos específicos.

\section{La gestión de los residuos municipales}

La cantidad de residuos municipales generados en Cataluña durante el año 2009 fue de 4,20 millones de toneladas (Saladié, 2011). Este valor representa un aumento del 20,8\% respecto a la cantidad recogida en el año 2000 cuando sólo fue de 3,48 millones. Desde entonces la generación ha ido en aumento hasta el año 2007 cuando se superaron los 4,3 millones. En los últimos años se ha producido una disminución y el valor del año 2009 es similar al del año 2005. Al contrario que para el conjunto de Cataluña, en la comarca de La Ribera d'Ebre la generación de residuos no ha parado de crecer desde el año 2000. De acuerdo con los datos facilitados por la Agència de Residus de Catalunya (ARC), en los últimos 10 años se ha pasado de un valor inferior a 8500 toneladas anuales a superar las 14500 , lo que significa que la generación de residuos en esta comarca ha aumentado un $71,6 \%$.

La gestión de los residuos domésticos debe ser llevada a cabo teniendo en cuenta sus características. La separación de los residuos debe realizarse una vez se han generado en el propio hogar. Pero esta separación en origen sólo tiene sentido si existen los recipientes apropiados para cada una de las fracciones de los residuos domésticos y esta posibilidad es relativamente reciente. Hasta no hace mucho tiempo todos los residuos se depositaban en bolsas de plástico en el interior de un recipiente, ya sea un cubo unifamiliar colgado en las fachadas de las casas en el caso de pueblos o bien en contenedores de mayor capacidad situados en las vías públicas (Figura 2). La recogida selectiva de los residuos municipales empezó a ser posible cuando apareció un nuevo mobiliario urbano donde se asociaba el color del contenedor al tipo de residuos que se tenía que depositar. Actualmente en algunos municipios tanto la recogida de la fracción resto como de la fracción orgánica se hace de nuevo puerta a puerta. Una vez que los ciudadanos depositan los residuos en 

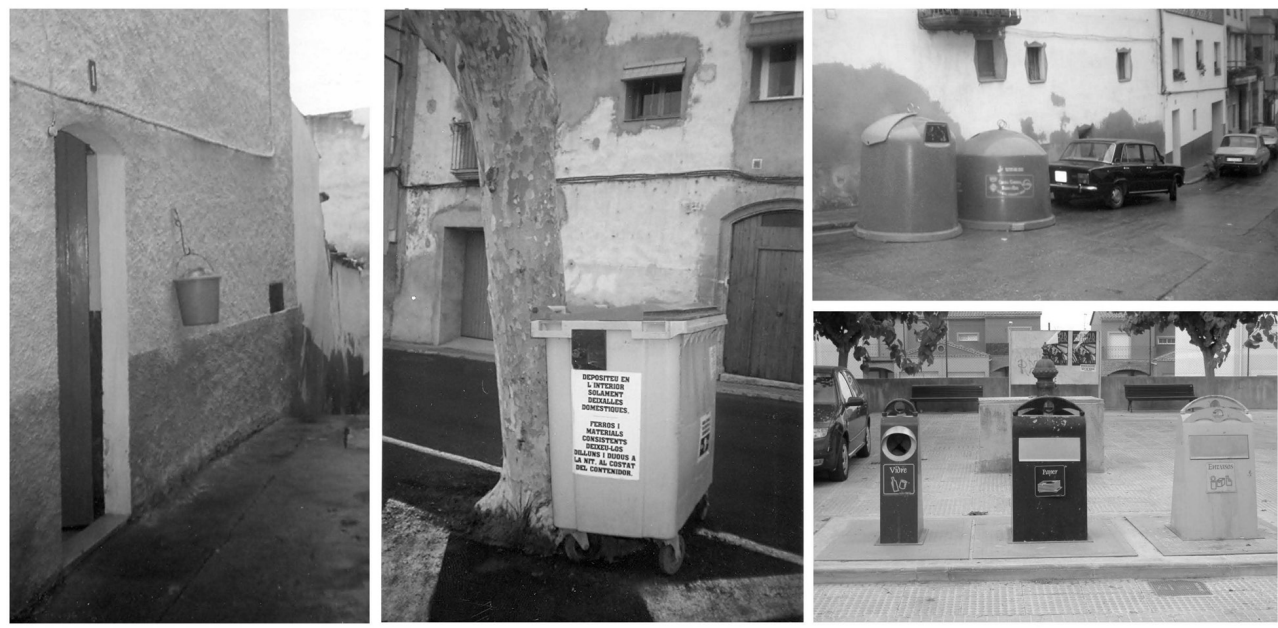

FIGURA 2. Contenedores de residuos municipales. Fotografías: O. Saladié.

los recipientes adecuados es el momento de la recogida, gestionada directamente por la administración o bien por una empresa que tiene la concesión de este servicio. Además de todos estos contenedores distribuidos por las calles de los núcleos de población también existen los llamados puntos verdes.

Cada una de las fracciones que forman parte de los residuos municipales tiene su tratamiento, por ejemplo la orgánica es enviada a las plantas de compostaje, de las cuales había en Cataluña en el año 2009 un total de 21. Como ya se ha indicado con anterioridad, la gestión de aquellos residuos municipales que no pueden ser ni reciclados ni reutilizados termina en un vertedero controlado o en una planta incineradora. En cuanto a los vertederos controlados, y partiendo de la base que tanto el diseño como los diferentes procesos de tratamiento de los residuos dentro de la instalación tienen que ser adecuados y funcionar perfectamente, la elección del lugar es clave. Y para esta elección hay que tener un conocimiento importante del territorio, especialmente de los aspectos del medio físico: geología, hidrología, climatología y biología. Según el Real Decreto 1481/2001, de 27 de diciembre, por el cual se regula la eliminación de residuos mediante depósito en vertedero, las consideraciones que se deben tener en cuenta a la hora de ubicar un depósito de residuos son las distancias entre el límite del depósito y las zonas residenciales y recreativas, vías fluviales, masas de agua y otras zonas agrícolas o urbanas; la existencia en las inmediaciones de aguas subterráneas, aguas costeras o reservas naturales; las condiciones geológicas y hidrogeológicas de la zona; el riesgo de inundaciones, hundimientos y corrimientos de tierras al emplazamiento del vertedero; y la protección del patrimonio natural o cultural de la zona. Por otra parte, la gestión de los residuos que se hace en una planta incineradora es muy clara. Se trata de un proceso de combustión controlada de los residuos con el cual se eliminan y se generan unos subproductos: cenizas, escorias y humos.

El año 2009 en Cataluña había operativas 4 plantas incineradoras de residuos municipales (Girona, Mataró, Sant Adrià de Besòs y Tarragona) y 25 vertederos controlados, uno de ellos situado en el municipio de Tivissa (Ribera d'Ebre).

La gestión de los residuos municipales, desde su origen hasta su posible valorización o tratamiento, tiene unos costes ambientales (Bernache, 2003), pero esta repercusión ambiental es, sin lugar a dudas, mucho mayor cuando la gestión está encaminada a la disposición 
final de los residuos (Meneses et al., 2009; Saladié y Oliveras, 2010). La cantidad de residuos municipales que no tendrían que ser enviados a un vertedero controlado o a una incineradora, es decir, que podrían ser reciclados y recuperados, se estima alrededor de un $80 \%$ del total generado. En Cataluña, como en el resto de España, todavía estamos muy lejos de esta cifra y en el caso catalán únicamente representa un 37,5\%. Mucho mejor es la situación en la comarca de La Ribera d'Ebre donde la cantidad de los residuos municipales que no va a disposición final es de un 56,9\% (Saladié, 2011).

\section{Los antiguos vertederos de residuos}

El mes de agosto del año 1994 entró en funcionamiento el vertedero controlado de residuos de la comarca de La Ribera d'Ebre situado en el municipio de Tivissa, concretamente en la zona de Els Magarells (Noroeste del termino municipal). El vaso del vertedero aprovechaba la morfología del barranco de Brull. Los núcleos urbanos situados a una menor distancia son Darmós que se encuentra a unos $2 \mathrm{~km}$ dirección Norte desde el vertedero y Móra la Nova, población que se encuentra a unos $3 \mathrm{~km}$ en dirección Noroeste. Actualmente esta infraestructura se encuentra fuera de servicio y, en paralelo a su clausura, empezó a funcionar un nuevo vertedero que se situó a continuación del antiguo siguiendo el barranco de Brull en dirección Noroeste. También se encuentra situado en el término municipal de Tivissa, aunque justo en el límite con el municipio vecino de Móra la Nova.

Al mismo tiempo que el primer vertedero comarcal empezó a recibir los residuos municipales generados en La Ribera d'Ebre se inició la clausura de los vertederos de los diferentes pueblos de la comarca. Las primeras localidades en llevar los residuos fueron Móra d'Ebre y Móra la Nova ya en el año 1994, a los que siguieron el resto de poblaciones. En ese momento todos los pueblos de la comarca tenían un vertedero de residuos a excepción de La Torre del Español, Darmós y Llaberia. En los dos primeros casos los residuos generados se trasladaban, respectivamente, al vertedero de Vinebre y al vertedero de La Serra d'Almos. Por lo que respecta a Llaberia no contaba con población residente. Así pues el número de vertederos municipales analizados en el presente trabajo es de 14, los cuales daban servicio a 16 poblaciones.

\subsection{Proximidad al núcleo urbano y accesibilidad}

El transporte de los residuos hasta el actual vertedero comarcal controlado se realiza mediante camiones adaptados para dicho servicio, aunque en algunas poblaciones debido a su complicado entramado urbano los residuos, una vez recogidos por un vehículo de dimensiones más pequeñas, son llevados a una estación de transferencia desde donde posteriormente se trasladan al vertedero controlado. Con anterioridad a la existencia del vertedero comarcal controlado únicamente en las poblaciones de Flix y de Móra d'Ebre los residuos eran recogidos en camiones y transportados hasta sus respectivos vertederos municipales. En el resto de núcleos urbanos los residuos eran recogidos y vertidos en un remolque tirado por un tractor o, más antiguamente, por un animal. Independientemente que la elección del terreno fuera más o menos acertada desde un punto de vista ambiental, en dicha elección era determinante la distancia que un vehículo lento, como es un tractor tirando un remolque lleno de basura, tenía que recorrer hasta el vertedero.

Las Tablas 1 y 2 muestran, junto con las coordenadas geográficas de los vertederos, la distancia en línea recta entre el vertedero y el respectivo núcleo urbano, la dirección en que se encontraba respecto al núcleo de población y la distancia real en ruta que el camión o el tractor tenía que recorrer. En referencia a esta distancia en ruta entre el núcleo de población 
Tabla 1

LOCALIZACIÓN Y DISTANCIA EN LÍNEA RECTA DE LOS VERTEDEROS DE RESIDUOS DE LA COMARCA DE LA RIBERA D'EBRE RESPECTO AL NÚCLEO DE POBLACIÓN

\begin{tabular}{|c|c|c|c|c|}
\hline Población & Latitud (N) & Longitud (E) & Distancia línea recta & Dirección \\
\hline Ascó & $41^{\circ} 10^{\prime} 27^{\prime \prime}$ & $0^{\circ} 34^{\prime} 22^{\prime \prime}$ & $405 \mathrm{~m}$ & SE \\
\hline Benissanet & $41^{\circ} 04^{\prime} 13^{\prime \prime}$ & $0^{\circ} 36^{\prime} 45^{\prime \prime}$ & $1950 \mathrm{~m}$ & NO \\
\hline Darmós & \multicolumn{2}{|c|}{ Vertedero de La Serra d'Almos } & $3465 \mathrm{~m}$ & SE \\
\hline Flix & $41^{\circ} 16^{\prime} 01^{\prime \prime}$ & $0^{\circ} 32^{\prime} 29^{\prime \prime}$ & $3950 \mathrm{~m}$ & $\mathrm{~N}$ \\
\hline Garcia & $41^{\circ} 07^{\prime} 10^{\prime \prime}$ & $0^{\circ} 39^{\prime} 13^{\prime \prime}$ & $825 \mathrm{~m}$ & $\mathrm{~S}$ \\
\hline Ginestar & $41^{\circ} 01^{\prime} 54^{\prime \prime}$ & $0^{\circ} 37^{\prime} 38^{\prime \prime}$ & $850 \mathrm{~m}$ & SO \\
\hline Miravet & $41^{\circ} 02^{\prime} 53^{\prime \prime}$ & $0^{\circ} 35^{\prime} 56^{\prime \prime}$ & $750 \mathrm{~m}$ & $\mathrm{~N}$ \\
\hline Móra d'Ebre & $41^{\circ} 04^{\prime} 41^{\prime \prime}$ & $0^{\circ} 38^{\prime} 04^{\prime \prime}$ & $850 \mathrm{~m}$ & $\mathrm{~S}$ \\
\hline Móra la Nova & $41^{\circ} 05^{\prime} 12^{\prime \prime}$ & $0^{\circ} 40^{\prime} 05^{\prime \prime}$ & $2070 \mathrm{~m}$ & SE \\
\hline La Palma d'Ebre & $41^{\circ} 17^{\prime} 13^{\prime \prime}$ & 0'39'53', & $100 \mathrm{~m}$ & $\mathrm{~N}$ \\
\hline Rasquera & $40^{\circ} 59^{\prime} 10^{\prime \prime}$ & $0^{\circ} 35^{\prime} 02^{\prime \prime}$ & $2000 \mathrm{~m}$ & $\mathrm{SO}$ \\
\hline Riba-roja d'Ebre & $41^{\circ} 14^{\prime} 43^{\prime \prime}$ & $0^{\circ} 29^{\prime} 23^{\prime \prime}$ & $500 \mathrm{~m}$ & $\mathrm{~S}$ \\
\hline La Serra d'Almos & $41^{\circ} 04^{\prime} 79^{\prime \prime}$ & $0^{\circ} 44^{\prime} 11^{\prime \prime}$ & $830 \mathrm{~m}$ & $\mathrm{SO}$ \\
\hline Tivissa & $41^{\circ} 02^{\prime} 32^{\prime \prime}$ & 0'43'32”' & $570 \mathrm{~m}$ & $\mathrm{O}$ \\
\hline La Torre de l'Esp. & \multicolumn{2}{|c|}{ Vertedero de Vinebre } & $2920 \mathrm{~m}$ & $\mathrm{O}$ \\
\hline Vinebre & $41^{\circ} 11^{\prime} 19^{\prime \prime}$ & $0^{\circ} 35^{\prime} 18^{\prime \prime}$ & $400 \mathrm{~m}$ & $\mathrm{~N}$ \\
\hline
\end{tabular}

Elaboración propia.

y el vertedero también se indica qué parte del recorrido se realizaba por carretera y qué parte se realizaba por camino. Muchos de estos caminos actualmente tienen el piso de cemento o bien están asfaltados, pero en los años 90 del siglo XX eran caminos de tierra. En algunos casos la distancia actual entre el emplazamiento del antiguo vertedero y el núcleo urbano es menor debido al crecimiento experimentado en los últimos años por parte de este último.

Si analizamos la distancia que tenía que recorrer el vehículo encargado del transporte de los residuos, en 7 de las 16 poblaciones el vertedero estaba situado a menos de $1 \mathrm{~km}$ de distancia en ruta, un número de poblaciones que aumenta hasta 10 si se considera la distancia en línea recta. Destaca por su proximidad al núcleo urbano el vertedero de La Palma d'Ebre que se encontraba a escasos 100 metros del núcleo urbano en línea recta mientras que eran unos 250 metros la distancia a recorrer desde el perímetro del núcleo urbano. También tenían que recorrer distancias muy cortas ( $<500$ metros) los vehículos encargados del transporte de los residuos de las poblaciones de Ascó y Vinebre. 
Tabla 2

LOCALIZACIÓN Y DISTANCIA EN RUTA DE LOS VERTEDEROS DE RESIDUOS DE LA COMARCA DE LA RIBERA D'EBRE RESPECTO AL NÚCLEO DE POBLACIÓN

\begin{tabular}{|l|c|c|c|c|}
\hline \multirow{2}{*}{ Población } & \multicolumn{3}{|c|}{ Distancia en ruta } & \multirow{2}{*}{$\begin{array}{c}\text { Carretera de } \\
\text { acceso }\end{array}$} \\
\cline { 2 - 4 } & Total & Carretera & Camino & C-12b \\
\hline Ascó & $460 \mathrm{~m}$ & $390 \mathrm{~m}$ & $70 \mathrm{~m}$ & T-324 \\
\hline Darmissanet & $2085 \mathrm{~m}$ & $845 \mathrm{~m}$ & $1240 \mathrm{~m}$ & TV-303 \\
\hline Flix & $4380 \mathrm{~m}$ & $2720 \mathrm{~m}$ & $1660 \mathrm{~m}$ & C-12 \\
\hline Garcia & $4695 \mathrm{~m}$ & $4440 \mathrm{~m}$ & $295 \mathrm{~m}$ & C-12 \\
\hline Ginestar & $935 \mathrm{~m}$ & $590 \mathrm{~m}$ & $345 \mathrm{~m}$ & C-12 \\
\hline Miravet & $1045 \mathrm{~m}$ & $660 \mathrm{~m}$ & $385 \mathrm{~m}$ & T-324 \\
\hline Móra d'Ebre & $820 \mathrm{~m}$ & $810 \mathrm{~m}$ & $10 \mathrm{~m}$ & T-324 \\
\hline Móra la Nova & $1015 \mathrm{~m}$ & $950 \mathrm{~m}$ & $65 \mathrm{~m}$ & C-12 \\
\hline La Palma d'Ebre & $2220 \mathrm{~m}$ & $1100 \mathrm{~m}$ & $1120 \mathrm{~m}$ & no carretera \\
\hline Rasquera & $250 \mathrm{~m}$ & $0 \mathrm{~m}$ & $250 \mathrm{~m}$ & TV-3201 \\
\hline Riba-roja d'Ebre & $870 \mathrm{~m}$ & $0 \mathrm{~m}$ & $870 \mathrm{~m}$ & no carretera \\
\hline La Serra d'Almos & $1055 \mathrm{~m}$ & $0 \mathrm{~m}$ & $1055 \mathrm{~m}$ & no carretera \\
\hline Tivissa & $925 \mathrm{~m}$ & $0 \mathrm{~m}$ & $925 \mathrm{~m}$ & no carretera \\
\hline La Torre de 1'Esp. & $3590 \mathrm{~m}$ & $2840 \mathrm{~m}$ & $750 \mathrm{~m}$ & T-714 \\
\hline Vinebre & $480 \mathrm{~m}$ & $0 \mathrm{~m}$ & $480 \mathrm{~m}$ & no carretera \\
\hline
\end{tabular}

Elaboración propia.

En el otro extremo se encuentra Flix, con el vertedero municipal situado a más de 4,5 $\mathrm{km}$ de distancia en ruta, aunque en este caso, ya en los años 90 del siglo XX la recogida y el transporte de los residuos se realizaba mediante un camión y no con un vehículo lento. También había que recorrer una distancia considerable en Darmós y La Torre de l'Espanyol, más de $4 \mathrm{~km}$ en el primer caso y poco más de $3,5 \mathrm{~km}$ en el segundo. No obstante, se trata de las dos poblaciones que en aquella época transportaban los residuos generados a los vertederos de poblaciones vecinas, cosa que explica la mayor distancia a recorrer. Finalmente destacar que tanto el vertedero de Rasquera como los de Móra la Nova y Benissanet se encontraban a más de $2 \mathrm{~km}$ de distancia en ruta del respectivo núcleo urbano.

En referencia a su accesibilidad, únicamente en 5 de las 16 poblaciones la localización del vertedero propiciaba que el acceso desde el núcleo urbano se realizase íntegramente a través de caminos sin necesidad de circular por carretera (La Palma d'Ebre, Riba-roja d'Ebre, La Serra d'Almos, Tivissa i Vinebre). En el resto de poblaciones el vehículo de transporte de los residuos tenía que recorrer una mayor o menor distancia por carretera combinando el recorrido con un último tramo por camino. La distancia desde la carretera de acceso hasta el vertedero era muy corta en Ascó, Miravet, Móra d’Ebre y Rasquera. 
En estos cuatro casos el vertedero prácticamente se encontraba a pie de carretera. En el resto de emplazamientos la visibilidad del vertedero quedaba limitada a excursionistas y, especialmente, a los propietarios de las fincas agrícolas cercanas. Al impacto visual del vertedero, hay que añadir los malos olores generados y el impacto producido por la dispersión de los residuos más volátiles, a consecuencia del viento. En la primera imagen de la figura 3 se observa el núcleo urbano de Ginestar y la localización del antiguo vertedero de residuos enmarcada en un cuadrado. La mayor parte del trayecto se realizaba por la carretera C-12 en dirección sur-oeste hacia Tortosa, que antiguamente recorría el núcleo urbano de Ginestar, para enlazar con un camino situado a mano izquierda de dicha carretera y que conducía hasta el vertedero. Por su parte, en la segunda imagen de la misma figura se observa la localización del antiguo vertedero de Tivissa respecto al núcleo de la población. A diferencia del caso anterior, en Tivissa el recorrido era totalmente por camino sin necesidad de tomar carretera alguna.

\subsection{El entorno de los vertederos}

La figura 3 muestra también las características del entorno donde estaban circunscritos los vertederos de residuos de Ginestar y de Tivissa y que se pueden extrapolar al resto de vertederos de la comarca de La Ribera d'Ebre. Se trata de un entorno mayoritariamente agrícola aunque en muchos casos se encuentran cercanos a masas de vegetación arbórea y arbustiva, de mayor o menor superficie. Entre los cultivos predominan los frutales en zonas de regadío o bien almendros y olivos si se trata de secanos. En el caso de la vegetación natural se trata mayoritariamente de bosques secundarios de pino blanco y matorral continental de romero y lino blanco.

El antiguo vertedero de Benissanet sería un claro ejemplo de localización en medio de parcelas agrícolas alejadas de la vegetación, como se puede observar en la figura 4a. Sin embargo lo más habitual era que, aunque los vertederos estuvieran situados en un entorno agrícola, tuvieran cerca vegetación natural. En la figura $4 \mathrm{~b}$ se observa el antiguo vertedero de Rasquera, cuando aún estaba en funcionamiento, muy cercano a la vegetación. Este vertedero estaba situado al lado de la carretera TV-3201 en dirección al balneario de Cardó, carretera que conduce a una zona montañosa de difícil accesibilidad y con una importante masa forestal. En una situación parecida se encontraban los antiguos vertederos de Ginestar, Tivissa (figura 4c) y La Serra d'Almos (figura 4d). El vertedero de Tivissa fue el origen de diferentes incendios forestales en los años 80 del siglo XX.

Otro aspecto a tener en cuenta del entorno más inmediato de los vertederos es su proximidad a cursos de agua o a barrancos. Algunos barrancos fueron aprovechados para ubicar los vertederos, como el barranco de Brull en el caso de Móra la Nova o el barranco de Els Plans en el de Garcia (figura 4e), cerca de la confluencia con el río Siurana. Otros muchos vertederos estaban cercanos a estructuras geomorfológicas por las cuales habitualmente no circula agua en superficie pero que puntualmente y después de episodios de lluvia de alta intensidad, pueden acoger importantes caudales de agua que circulan a velocidades elevadas: el barranco de Gàfols (vertedero de Ginestar), el barranco de les Eixugueres (vertedero de Miravet), el Riu Sec (vertedero de Móra d'Ebre), el barranco de Els Montblanquets (vertedero de La Palma d'Ebre), el barranco de Els Palancars (vertedero de La Serra d'Almos) o el barranco de Padrells (vertedero de Tivissa).

El río Ebro vertebra la comarca de La Ribera d'Ebre y muchas de sus poblaciones se encuentran en su orilla o en sus proximidades. Por estar razón, algunos de los antiguos vertederos se encontraban a distancias inferiores a $1 \mathrm{~km}$ del curso del río Ebro: el de Ginestar en dirección noroeste, el de Riba-roja d'Ebre tanto en dirección este como noroeste 
o el de Garcia que también tiene el río Ebro en dirección noroeste al cuál hay que añadir la presencia del río Siurana a escasos 300 metros en línea recta dirección norte. El antiguo vertedero de Ascó (Figura 4f) era el más cercano al curso del río Ebro, se encontraba a unos 50 metros en dirección norte, en paralelo a la línea de ferrocarril entre Barcelona y Zaragoza.

\subsection{El espacio destinado a vertedero}

La totalidad de vertederos de residuos analizados en el presente trabajo estaban situados en terrenos de los respectivos ayuntamientos, es decir, eran y continúan siendo terrenos de propiedad municipal donde, por un período más o menos largo de tiempo y hasta la segunda mitad de los años 90 del siglo XX, fueron acogidos los residuos generados en los diferentes pueblos de la comarca de La Ribera d'Ebre. Existe una gran variedad en la morfología de los emplazamientos, pero se pueden agrupar de una manera genérica entre aquellos que se encontraban en una explanada y aquellos en que se aprovechaba un talud.

A excepción de los vertederos de Garcia y Riba-roja d'Ebre, el perímetro de los restantes doce estaban cerrados por una valla. En algunos casos este cierre estaba en muy malas condiciones poco antes de su clausura. De todos los vertederos de la comarca el que ocupaba una mayor superficie era el de Flix con unos $9500 \mathrm{~m}^{2}$. Por su parte el de Móra d'Ebre tenía una superficie de unos $5000 \mathrm{~m}^{2}$. En el otro extremo se encontraban los vertederos de La Serra d'Almos, Garcia y Vinebre que no llegaban a los $500 \mathrm{~m}^{2}$. El vertedero de Benissanet tenía una $900 \mathrm{~m}^{2}$ de superficie, estaba vallado y tal y como se puede observar en la figura 4a ocupaba la parte central de una parcela de unos $5200 \mathrm{~m}^{2}$ donde también se acumulaban residuos.

El vertedero de Benissanet es un claro ejemplo de vertedero situado en una explanada y con el recinto vallado donde se acumulan los residuos. También se encontraban en explanadas los vertederos de Móra d'Ebre, Rasquera, Miravet, y Vinebre. En el caso de Rasquera estaba situado en un extremo de la explanada junto a un talud que estaba a un nivel más bajo respecto al resto de la explanada, con lo cual era posible aumentar su capacidad y en el de Vinebre se había practicado una rasa.

En el resto los residuos eran vertidos por un talud de pendiente más o menos pronunciada, acumulándose los escombros en el fondo. El vertedero de Ginestar es el que presentaba un desnivel menor entre el punto desde donde se procedía al vertido y el lugar donde se acumulaban los residuos. Ya más pronunciada era la pendiente de los antiguos vertederos de Tivissa y Riba-roja d'Ebre, aunque era en los de Ascó, La Serra d'Almos, Garcia y Móra la Nova donde el desnivel era muy importante. En estos dos últimos casos los residuos eran tirados a un barranco y los vertederos se formaron por la propia caída libre de los residuos. La figura 4e muestra la imagen del antiguo vertedero de Garcia en el año 1995 con los residuos acumulados en el fondo del barranco de Els Plans y siguiendo el talud hasta la cota superior desde donde se tiraban.

Mención aparte merecen los vertederos de La Palma d'Ebre y de Flix. El primero (figura $4 \mathrm{~g}$ ) por tratarse de una terraza a la cual eran vertidos los residuos desde el terreno inmediatamente superior a través de dos puertas situadas en el vallado que encierra el perímetro del vertedero. Cuando la acumulación de residuos era importante eran trasladados al extremo opuesto del emplazamiento. En el caso de Flix el vertedero estaba situado en un terreno estructurado en una sucesión de plataformas en pendiente, aunque poco acentuada. La figura 5 muestra un mapa que forma parte del proyecto de clausura del vertedero de residuos de Flix donde queda clara la disposición de las curvas de nivel y se indica la localización del vertedero. 

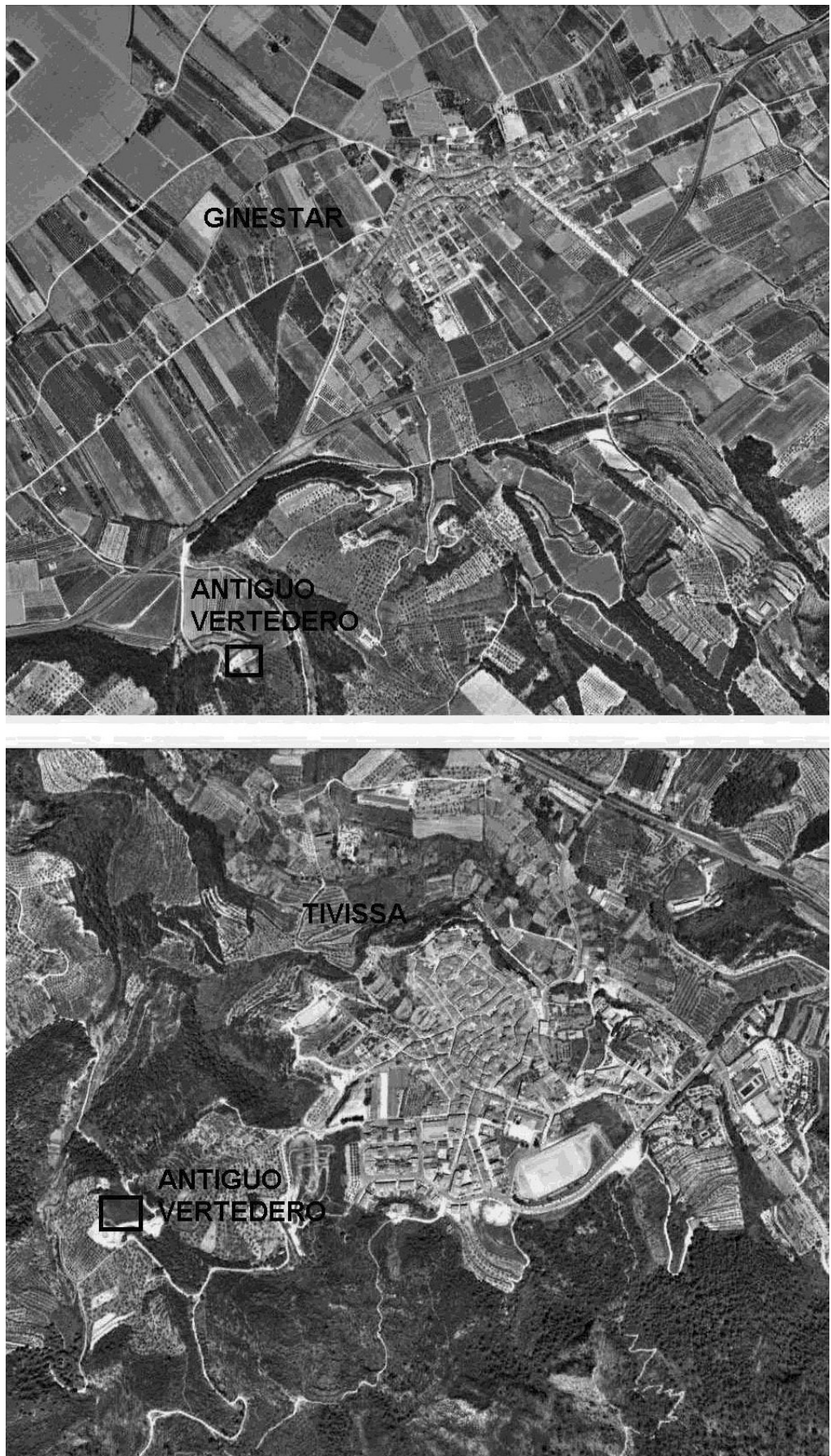

FIgURA 3. Localización de los antiguos vertederos de residuos de Ginestar (arriba) y de Tivissa (abajo). Fuente: Institut Cartogràfic de Catalunya y elaboración propia. 

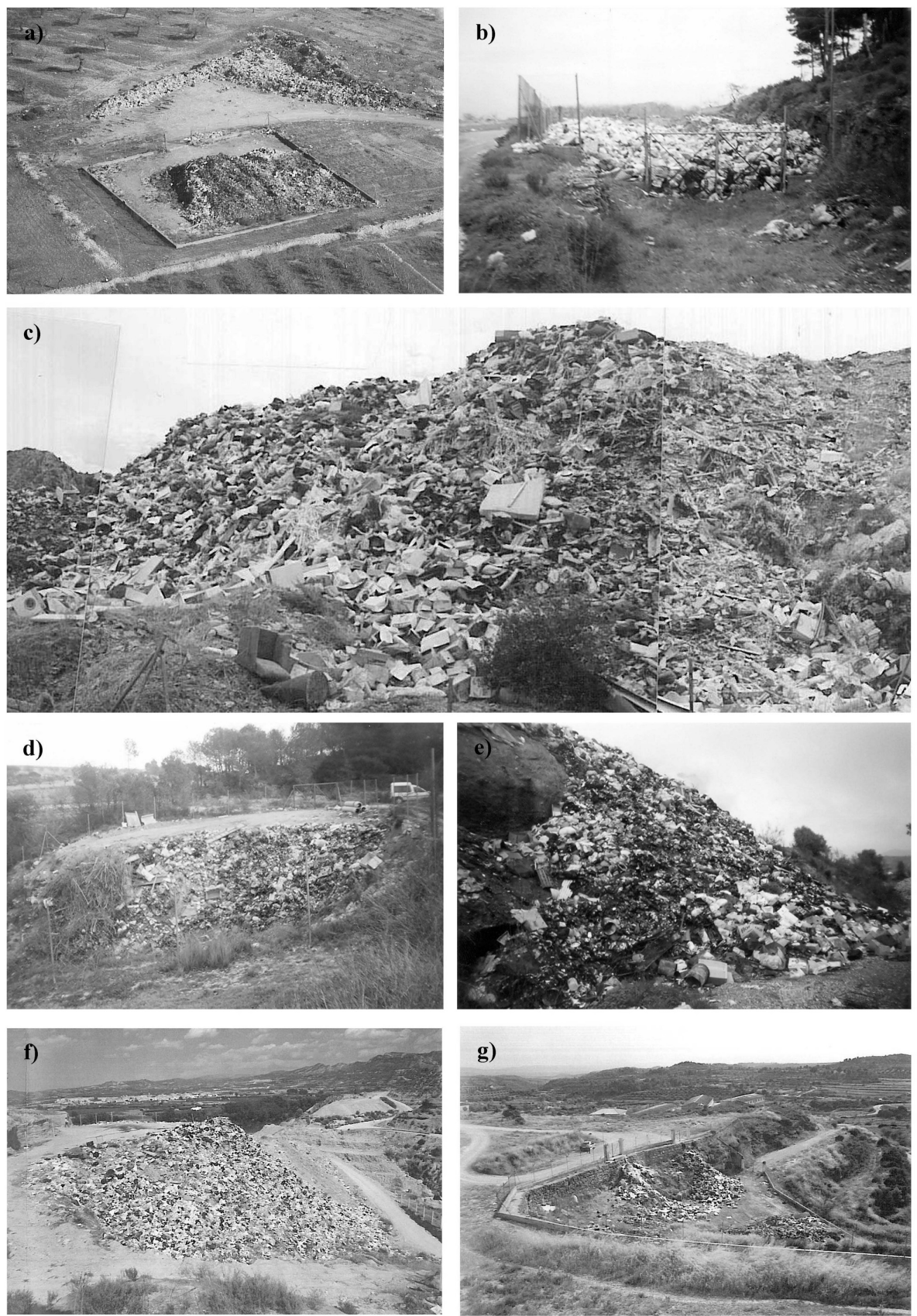

Figura 4. Antiguos vertederos de Benissanet (a), Rasquera (b), Tivissa (c), La Serra d'Almos (d), Garcia (e), Ascó (f) y La Palma d'Ebre (g) a mediados de los años 90 del siglo XX.

Fotografías: Consell Comarcal de la Ribera d'Ebre (fotografías a, c, f yg) y O. Saladié (fotografías b, d y e). 
El último aspecto a analizar en este subapartado es el de los materiales que conforman el espacio destinado a vertedero. Un total de 8 vertederos se encontraban sobre materiales recientes del Cuaternario. Se trata de materiales sedimentarios detríticos, ya sea del Holoceno (Garcia y Móra d'Ebre) o bien del Pleistoceno medio y superior (Benissanet, Ginestar, Miravet, Móra la Nova, La Serra d'Almos y Vinebre). Únicamente el vertedero de Móra d'Ebre se encontraba directamente sobre la terraza del río Ebro con un predomino claro de arenas, gravas y limos en superficie. No obstante los otros 7 estaban sobre terrenos de aluvión o bien en conos de deyección, con lo cuál también predominan arenas y gravas, a los que hay que añadir la presencia de arcillas y bloques.

Los antiguos vertederos de Ascó, Flix, La Palma d'Ebre y Riba-roja d'Ebre (sector septentrional de la comarca de Ribera d'Ebre) estaban también sobre materiales sedimentarios, aunque más antiguos que los anteriores, concretamente del Paleógeno (subperíodo del Terciario). En el caso de Riba-roja d'Ebre y especialmente en Ascó, los terrenos se encuentran al límite con la terraza fluvial del río Ebro, pero su disposición en una altura superior a la terraza fluvial da como resultado la presencia de lutitas (limos y arcillas) con incrustaciones de arenisca y microconglomerados. Esta misma configuración de materiales también se da en el antiguo vertedero de Flix, mientras que en el de La Palma d'Ebre, ya más alejado del río, destaca la presencia de conglomerados.

Finalmente, los materiales más antiguos son los que se encuentran en los vertederos de Rasquera y de Tivissa. Se trata de terrenos del Mesozoico, concretamente del Triásico. En el caso de Rasquera predominan margas (roca sedimentaria arcillosa) y calizas margosas, mientras que en el de Tivissa destaca la presencia de dolomías y calizas.

\subsection{La gestión final de los residuos en el vertedero}

En un depósito controlado los residuos son enterrados previa compactación de los mismos. El hecho de no quedar a la intemperie evita la dispersión de los residuos y una posible combustión espontánea con riesgo de producir un incendio forestal. Asimismo, este soterramiento significa una disminución de los malos olores y de la presencia de insectos y roedores. Con la compactación previa de los residuos se consigue ganar espacio (vida útil del depósito) así como también se extrae de los residuos gran parte del agua que contienen, cosa que repercutirá positivamente en una disminución de los líquidos lixiviados generados en el vaso del depósito y que han de ser tratados. Estos depósitos controlados tienen que situarse en lugares donde haya una presencia importante de materiales impermeables (como por ejemplo arcilla) que actuarán como barrera geológica natural e impedirán la contaminación de los suelos y de las aguas subterráneas en caso de que las haya. No obstante, la preservación de suelos y aguas no ha de limitarse únicamente a esta impermeabilización natural, sino que es necesario que el vaso esté recubierto por una barrera geológica artificial. A su vez, los residuos han de descansar sobre una capa de drenaje, como por ejemplo gravas, para llevar a cabo la recogida de los líquidos lixiviados y del agua de lluvia. También es necesario facilitar la salida al exterior del biogás generado por la acumulación de los residuos mediante unos conductos en forma de chimenea.

La gestión final de los residuos en el vertedero de Flix era la más parecida a la que se realiza en un depósito controlado. El terreno donde los residuos eran periódicamente enterrados estaba impermeabilizado, existía una instalación de recogida de los líquidos lixiviados, disponía de una red de drenaje inferior con grava y geotextil, y también un sistema de drenaje superior, gracias a la existencia de unas rasas. En el resto de vertederos de la comarca la gestión final consistía en la disposición de los mismos en superficie llevando a cabo en la mayoría de los casos la quema de los residuos con el objetivo de reducir su 


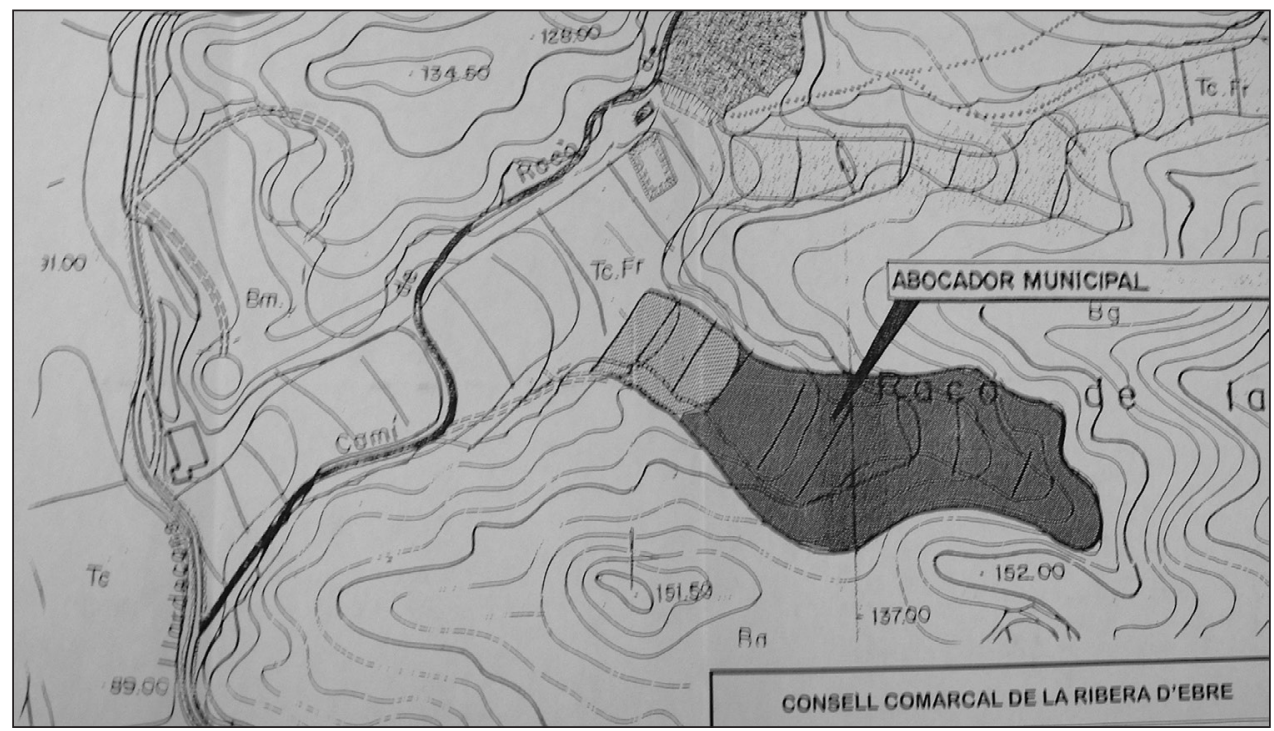

Figura 5. Mapa de localización del antiguo vertedero de residuos de Flix. Fuente: Consell Comarcal de la Ribera d'Ebre.

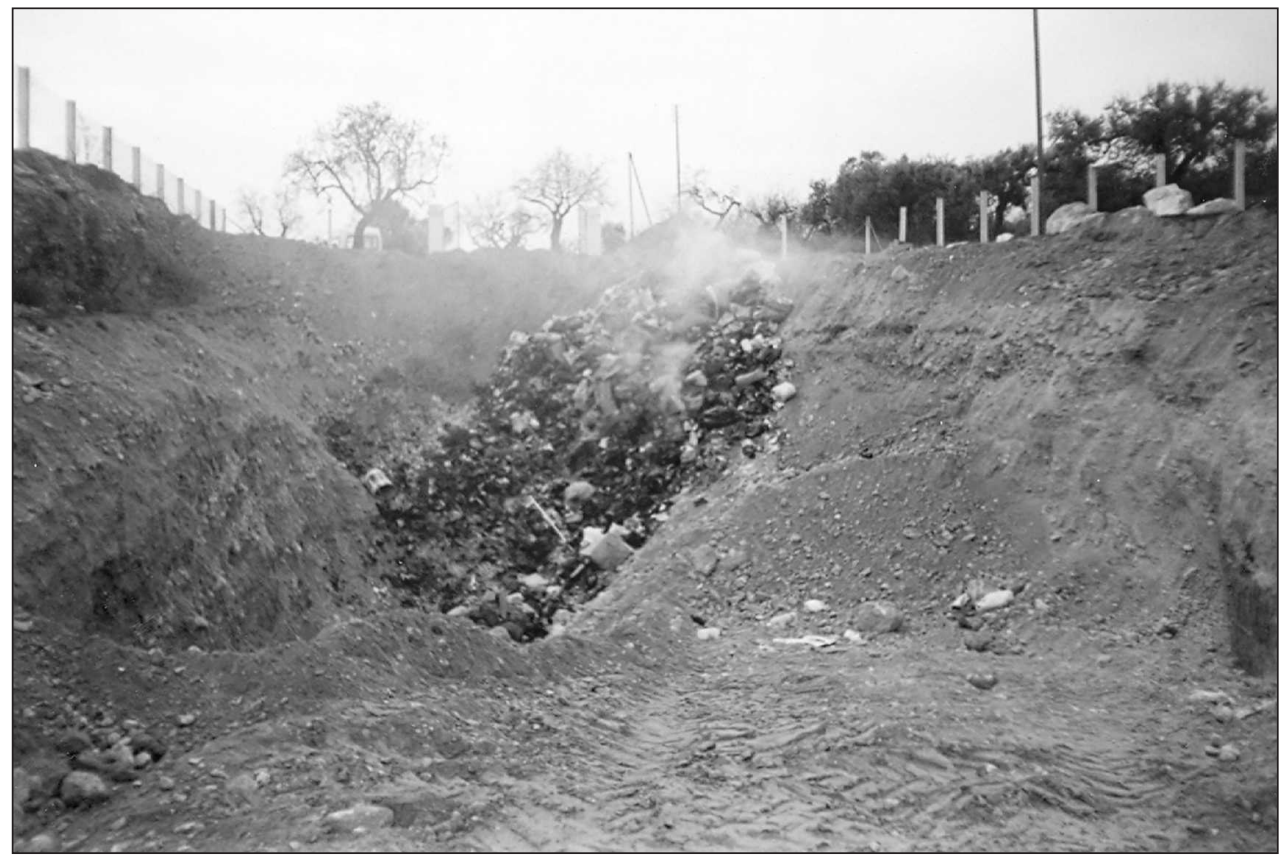

FIGURA 6. Detalle del antiguo vertedero de Miravet en 1995. Fotografía: O. Saladié. 
volumen, aunque a veces la combustión se originaba de forma espontánea. Era habitual que en las inmediaciones del vertedero se dispersaran parte de los residuos más volátiles, como plásticos o papeles, debido a la acción del viento. Aunque la mayoría de los vertederos sólo eran visibles desde zonas cercanas, podían ser localizados a lo lejos por una permanente columna de humo producto de la combustión de los residuos.

En el vertedero de Rasquera, como en el de Flix, tampoco se practicaba la quema de los residuos, esto explica que poco antes de su clausura estuviera prácticamente lleno, tal y como se observa en la figura $4 \mathrm{~b}$. Por otra parte, en la figura $4 \mathrm{e}$, correspondiente al vertedero de Garcia, se observan residuos que fueron vertidos por el talud del barranco poco tiempo antes de ser tomada la fotografía junto con materiales de color oscuro producto de una combustión de los residuos llevada a cabo con anterioridad. Finalmente hay que mencionar el caso de Miravet. Su vertedero ocupaba una parcela de forma rectangular y de superficie llana que contaba con el perímetro vallado. No obstante, los residuos se depositaban en un agujero excavado en el suelo, periódicamente eran quemados (Figura 6) y posteriormente enterrados.

\subsection{Proceso de clausura de los vertederos y situación actual}

La gestión de los residuos comprende un conjunto de actividades entre las cuales se encuentran la recogida de los residuos, su transporte, almacenamiento, valorización, tratamiento y disposición. Pero esta gestión no estaría completa sin tener en cuenta la vigilancia de los vertederos donde se realiza la disposición de los residuos, así como su clausura y sellado. En el caso de los vertederos de residuos de las diferentes poblaciones de la comarca de La Ribera d'Ebre su clausura se llevó a cabo durante la segunda mitad de la década de los años 90 del siglo XX bajo la dirección y supervisión del Consell Comarcal de la Ribera d'Ebre y de la Junta de Residus de Catalunya (actualmente Agència de Residus de Catalunya).

La clausura menos complicada desde un punto de vista técnico fue la del vertedero de Flix puesto que, tal y como ya hemos comentado, en este vertedero los residuos eran gestionados de una manera similar a la que se realiza en un vertedero controlado. En el resto de vertederos los residuos eran dejados en una explanada o tirados por un talud, quedando al aire libre, pudiendo ser posteriormente quemados. En consecuencia la opción de clausura y sellado de estos vertederos consistió en el confinamiento de los residuos existentes ya sea en un agujero excavado en el mismo emplazamiento o bien aprovechando el tramo inferior del margen cóncavo del talud por el cual fueron vertidos los residuos.

La figura 7 muestra el emplazamiento del vertedero de Ginestar con el perímetro vallado. En ese momento el vertedero estaba clausurado y sólo era utilizado como planta de transferencia de los residuos que eran transportados hasta el vertedero controlado comarcal, tal y como se desprende del contenedor verde situado en el centro y de la rampa que conducía hasta el contenedor desde donde tirar los residuos en su interior. No obstante el vertedero todavía no había sido sellado, puesto que al fondo de dicha imagen pueden apreciarse los residuos acumulados hasta ese momento. Dichos residuos fueron posteriormente confinados en un agujero practicado en la misma zona donde se encontraban y que ya contaba con una pequeña pendiente. A continuación fueron cubiertos de una capa de arcilla de unos 30 cm de espesor para la impermeabilización del terreno e inmediatamente encima de esta se situó otra capa de tierra fina de unos $50 \mathrm{~cm}$ de espesor apta para la posterior siembra de vegetación. De acuerdo con el proyecto de clausura, deberían ser gramíneas y leguminosas (figura 8 - arriba).

El proceso llevado a cabo en el resto de vertederos fue muy similar, ya sea en aquellos en que se aprovechó el talud para el confinamiento de los residuos (figura 8 - abajo) 


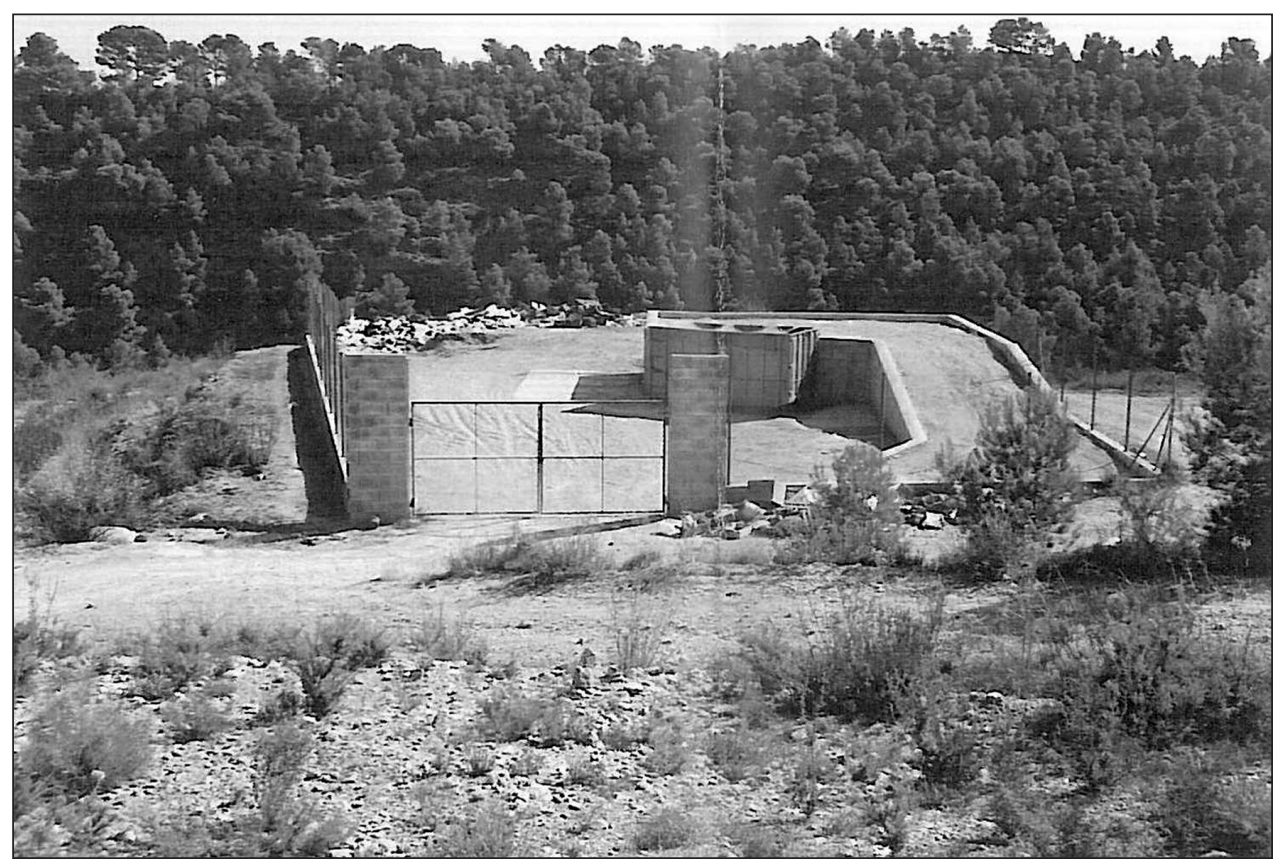

Figura 7. Vista exterior del antiguo vertedero de Ginestar en 1996. Fuente: Consell Comarcal de la Ribera d'Ebre.

o en aquellos en que el emplazamiento estaba situado en una explanada donde tuvo que practicarse una excavación de mayor envergadura para crear el hoyo donde confinar los residuos. En algunos vertederos entre la capa de arcilla en contacto con los residuos y la capa de tierra superior se situó una capa de grava como drenaje. En el caso del vertedero de Vinebre la clausura y sellado consistió simplemente en cubrir con una sucesión de capas de arcilla, grava y tierra la rasa en la cual se encontraban los residuos. En aquellos vertederos en que fue necesario se practicaron rasas perimetrales con el objetivo de desviar las aguas pluviales y evitar los posibles problemas generados por la escorrentía. En todos ellos se procedió a la desinsectación y desratización de la zona. Los procesos de clausura y sellado de los vertederos de residuos de la comarca de La Ribera d'Ebre fue muy parecido en todos los casos, aunque se tuvieron en cuenta y se produjeron las adaptaciones necesarias a la características de cada uno de ellos.

Donde ha habido diferencias es en el nuevo uso de los terrenos y la situación actual de los mismos. En algunos casos el emplazamiento fue aprovechado como estación de transferencia de residuos. Esa fue la opción en Ginestar, tal y como se ha indicado anteriormente, pero también en Miravet y en Rasquera. La estación de transferencia de Tivissa estaba cerca del antiguo vertedero. En los casos de los vertederos de Ascó y de Móra d'Ebre una parte de los terrenos se ha aprovechado para instalar un punto verde, es decir, un lugar donde la población puede llevar la mayoría de los residuos domésticos reciclables (excepto la materia orgánica y los medicamentos) junto con otros materiales como neumáticos, baterías, chatarra, pinturas, aceites vegetales minerales usados, textil, electrodomésticos, muebles y residuos domésticos voluminosos. 


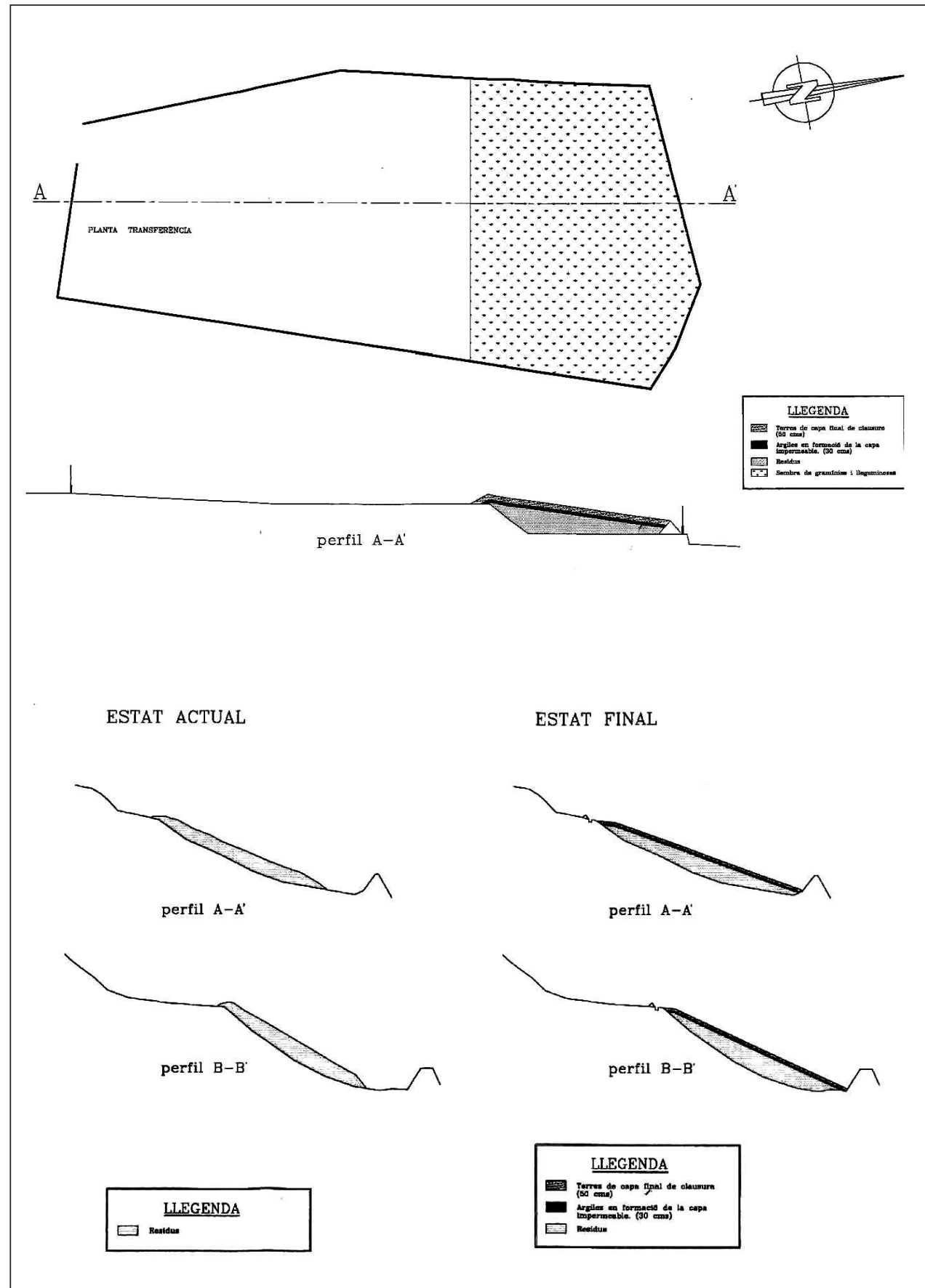

FIGURA 8. Planta y perfil del antiguo vertedero de Ginestar (arriba) y perfil del antiguo vertedero de Ascó (abajo), correspondientes a los proyectos de clausura. Fuente: Consell Comarcal de la Ribera d'Ebre. 

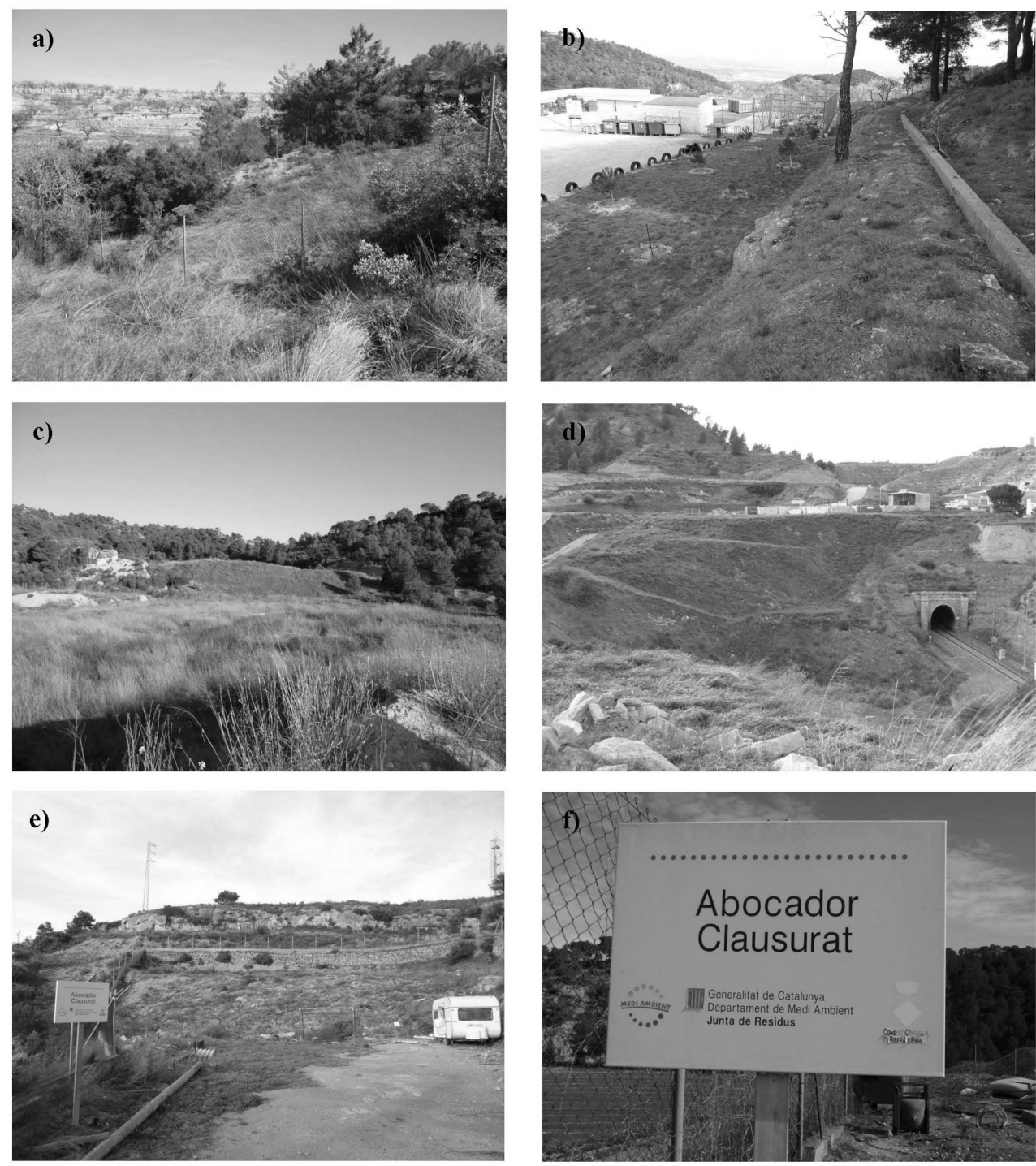

FIgURA 9. Imágenes de los terrenos que albergaron los vertederos de residuos de La Serra d'Almos (a), Rasquera (b), Flix (c), Ascó (d) y La Palma d'Ebre (e) y señal de vertedero clausurado en Ginestar (f) (2010). Fotografías: R. Viñes.

Actualmente la mayoría de los terrenos de los antiguos vertederos de la comarca de La Ribera d'Ebre son campos yermos. En los casos de Garcia y Móra la Nova hay que tener en cuenta que ocupaban el margen de un barranco. En algunos casos el único indicio que en el pasado hubo un vertedero de residuos es una señal que informa de que nos encontramos en un vertedero clausurado. 
La figura 9 muestra diferentes imágenes de la situación actual de los terrenos que albergaron 6 de los vertederos de residuos domésticos de la comarca de la Ribera d'Ebre. Algunas de estas imágenes se pueden comparar con las de la figura 4 cuando los vertederos aún albergaban los residuos en superficie. De entre ellos queremos destacar el caso de Rasquera (Figura 9b), imagen que se puede comparar con la del mismo emplazamiento en la año 1995 poco antes de la clausura del vertedero (figura 4b). Puede observarse como el espacio ocupado antiguamente por los residuos está actualmente delimitado por una sucesión de neumáticos y que en la superficie se ha plantado la misma especie arbórea que existe en el talud que limita con el vertedero. Los residuos se encuentran enterrados debajo de la capa de tierra apta para el enraizamiento de la vegetación, de una capa de grava de drenaje y de una capa de arcilla impermeabilizante. En la actualidad los residuos son transportados desde Rasquera hasta este recinto y posteriormente son trasladados hasta el vertedero controlado comarcal.

\section{CONCLUSIONES}

El objetivo planteado en este trabajo de investigación se ha llevado a cabo y se han localizado e inventariado los antiguos vertederos municipales de residuos existentes en las diferentes poblaciones de la comarca catalana de La Ribera d'Ebre con anterioridad a transportar los residuos hasta el vertedero controlado comarcal que entró en funcionamiento en el año 1994. Además de establecer la localización de cada uno de ellos también se ha realizado un análisis descriptivo de sus características del emplazamiento (morfología, superficie, materiales, etc.) y del entorno más inmediato, así como su proximidad al núcleo urbano, accesibilidad y gestión de los residuos, a partir de las cuales es posible evaluar las potenciales repercusiones ambientales por el hecho que ese terreno fuera escogido como vertedero de residuos. De esta manera se ha generado una base de datos con sus características más importantes y con la situación actual de los terrenos más de 10 y en algunos casos más de 15 años después de su clausura y sellado. Se trata de un total de 14 espacios destinados en su momento a vertederos.

Esto ha sido posible gracias a la combinación de una exhaustiva búsqueda documental y un minucioso trabajo de campo. La búsqueda documental se ha realizado en la sede del Consell Comarcal de la Ribera d'Ebre. Fue desde el área de medioambiente de este organismo supramunicipal desde donde durante la segunda mitad de los años 90 del siglo XX se llevó a cabo el proceso de clausura y sellado de los vertederos municipales. El trabajo de campo ha consistido en la visita a los terrenos que durante muchos años tuvieron como función la recepción de los residuos domésticos generados por los habitantes de la comarca de Ribera d'Ebre. Los resultados mostrados son una síntesis de la gran cantidad de información recopilada para cada uno de los vertederos analizados en este trabajo. Información más detallada e imágenes antiguas y actuales de cualquiera de ellos pueden ser solicitadas por medio de correo electrónico (oscar.saladie@urv.cat).

A excepción del antiguo vertedero de residuos de Flix, el resto de emplazamientos presentaban importantes deficiencias desde un punto de vista ambiental, ya sea porque los residuos se quemaban, porque estaban sobre materiales permeables cercanos a cursos de agua, por su proximidad a núcleos urbanos, por su impacto visual (dispersión de los residuos por acción del viento) o por el riesgo sanitario generado por la presencia continuada de insectos y roedores. Ahora bien, la cantidad de residuos generados por habitante en el año 1995 en una comarca con un importante peso del sector agrícola era bastante inferior a la cantidad generada actualmente, así como tampoco había la presencia de ciertos productos residuales con un mayor potencial de degradación del medio ambiente. 
Finalmente, consideramos que la realización de este tipo de trabajos sobre los antiguos vertederos municipales de residuos y su difusión (exposiciones, conferencias, etc.) podría ser una herramienta complementaria en el momento de realizar las campañas de concienciación y sensibilización sobre la necesidad de reducir la cantidad de residuos generados y a su vez aumentar al máximo la cantidad de estos que son recogidos selectivamente y no son enviados a disposición final, ya sea a un vertedero controlado a una planta de incineración. La gestión de los residuos realizada en la comarca de La Ribera d'Ebre hasta finales del siglo XX, como en la gran mayoría de España, no era la adecuada y hay que mostrar a la población, especialmente a las generaciones más jóvenes, como se llevaba a cabo. No obstante, esto no significa que la gestión que se realiza actualmente no tenga ninguna repercusión ambiental.

\section{BIBLIOGRAFÍA}

AGÈNCIA DE RESIDUS DE CATALUNYA: Residus industrials, municipals i recollida selectiva a Catalunya. Departament de Medi Ambient i Habitatge de la Generalitat de Catalunya. Disponible en http://www.arc.cat.

ANUARI ECONÒMIC COMARCAL CATALUNYA CAIXA 2010. Disponible en http://www. caixacatalunya.com/caixacat/cat/ccpublic/particulars/publica/pdf/anuari2010.pdf.

BERNACHE, G. (2003): «The environmental impact of municipal waste management: the case of Guadalajara metro area», en Resources, Conservations and Recycling, n 39, pp. 223-237.

LÓPEZ, D. (1997): El medio ambiente. Editorial Cátedra, Madrid.

MENESES, M., J. PASQUALINO y F. CASTELLS (2009): «The sustainable consumption of domestic products: the environmental effect of packaging», en II Congrés Internacional de Mesura $i$ Modelització de la Sostenibilitat ICSSMM09, Càtedra UNESCO de Sostenibilitat de la Universitat Politècnica de Catalunya, Terrassa.

PROJECTES DE CLAUSURA DELS ABOCADORS MUNICIPALS DE RESIDUS DE LA COMARCA DE LA RIBERA D'EBRE. Consell Comarcal de la Ribera d'Ebre (varios años).

SALADIÉ, O. (2011): «Los residuos domésticos y asimilables en Cataluña: la generación y la recogida selectiva como indicadores de la sostenibilidad del desarrollo territorial», en Boletín de la Asociación de Geógrafos Españoles, n ${ }^{\circ}$ 56, pp. 321-347.

SALADIÉ, O. y J. OLIVERAS (2010): Desenvolupament sostenible, Publicacions URV, Tarragona. 